\title{
The seasonal cycle of sublimation at Halley, Antarctica
}

\author{
J. C. King, ${ }^{1}$ P. S. Anderson, ${ }^{1}$ G.W. Mann ${ }^{2}$ \\ ${ }^{1}$ British Antarctic Survey, Natural Environment Research Council, High Cross, Madingley Road, Cambridge CB3 0ET, England \\ ${ }^{2}$ School of the Environment, University of Leeds, Leeds LS2 977, England
}

\begin{abstract}
We have used micrometeorological data collected at Halley Research Station, Antarctica, to estimate monthly totals of snow sublimation. Direct sublimation from the snow surface is calculated using bulk-transfer formulae, while the sublimation of blowing snow is estimated using a model for suspended-particle number density and individual particle sublimation rates. During the winter months, sublimation losses are negligible, but between November and March sublimation removes around 25\% of the snowfall. Surface sublimation and sublimation of blowing snow make roughly equal contributions to this total. Estimates of sublimation using micrometeorological data agree well with estimates made from daily snow-stake measurements.
\end{abstract}

\section{INTRODUCTION}

The low air temperatures prevailing over Antarctica mean that the loss of surface mass by sublimation is relatively small compared to that occurring over temperate glaciers or the margins of the Greenland ice sheet. Nevertheless, it is not completely negligible when considering the mass balance of the Antarctic ice sheets, and surface sublimation may remove $10-15 \%$ of the precipitation falling on the continent (Van den Broeke, 1997). This is of the same order of magnitude as the uncertainties in the major terms (precipitation and iceberg calving) controlling the mass balance of the Antarctic ice sheets. Additionally, sublimation of surface snow can confound the interpretation of ice-core records by modifying concentrations of chemicals in the surface snow after deposition.

Sublimation from a snowfield or ice sheet may occur directly from the snow surface or, when wind speeds are high enough to cause snow to drift, from suspended snow particles. This latter mechanism could, intuitively, give rise to large sublimation losses since the surface area of snow exposed to the atmosphere is greatly increased and the ventilation of suspended snow particles is greater than that of surface snow. However, observational and modelling studies (Dover, 1993; King and others, 1996; Mann, 1998; Mann and others, 2000) indicate that, in Antarctica, sublimation rates during blowing snow are restricted by the high relative humidities which prevail during such conditions.

In this paper, we calculate both surface and blowingsnow sublimation from measurements made at Halley Research Station, Antarctica, over the period January 1995-January 1997. The methodology we use is similar to that employed by King and others (1996) to calculate sublimation rates at the same location over austral winter 1991. The longer data series available to us has enabled us to study the full annual cycle of sublimation, and improved instrumentation has reduced some of the uncertainties associated with the earlier measurements.

\section{METHODS}

\subsection{Site and instrumentation}

Halley Research Station $\left(75^{\circ} 35^{\prime} \mathrm{S}, 26^{\circ} 25^{\prime} \mathrm{W}\right.$ ) is situated on the Brunt Ice Shelf on the southeastern shore of the Weddell Sea at about $30 \mathrm{~m}$ a.s.l. The general climatology of the station is described by König-Langlo and others (1998). Monthly mean temperatures range from $-5^{\circ} \mathrm{C}$ in the summer months to $-30^{\circ} \mathrm{C}$ in mid-winter. Conditions at Halley are strongly influenced by weather systems moving across the Weddell Sea and by the coastal location of the station, which means that it experiences air masses which have originated both from over the Antarctic continent and from the Atlantic sector of the Southern Ocean. Humidity measurements (King and Anderson, 1999) indicate that the near-surface air is generally close to saturation with respect to ice, or even slightly supersaturated. Wind speeds are moderate for an Antarctic coastal location, with monthly means averaging $5-8 \mathrm{~m} \mathrm{~s}^{-1}$ throughout the year. However, winds become sufficiently strong to generate blowing snow for around $20-30 \%$ of the time.

The station lies about $15 \mathrm{~km}$ inland of the ice front, and the flat surface of the ice shelf extends a further $40 \mathrm{~km}$ inland to the grounding line. The prevailing easterly surface winds have an uninterrupted fetch of $>40 \mathrm{~km}$ over a very uniform ice-shelf surface. Hence, surface fluxes measured at Halley should be representative of those prevailing over a wide area surrounding the station. These ideal micrometeorological conditions led to Halley being used for surface flux studies during the austral winters of 1986 (King, 1990) and 1991 (King and Anderson, 1994). In 1995, further micrometeorological instrumentation was installed at the station, with the specific aim of making surface flux measurements over several annual cycles in order to establish a surface massand energy-balance climatology for the site.

The instruments used in this study were installed on a mast approximately $120 \mathrm{~m}$ south-southeast of the nearest building in the station complex. At this site, the prevailing 
easterly winds had a completely unobstructed fetch, while, with winds from the northwest quadrant, the mast was potentially in the wake of the building. However, $<2 \%$ of winds blow from this sector, so the majority of measurements are representative of undisturbed flow.

Table 1 lists the instruments referred to in this paper. A Kaijo Denki DAT-300 sonic anemometer provided measurements of mean wind speed and eddy-correlation estimates of heat and momentum fluxes at a nominal height of $4 \mathrm{~m}$. Heaters were fitted to the ultrasonic transducers in order to prevent the formation of rime that had proved to be a problem in earlier work at this location. The addition of heating greatly improved the availability of reliable data from this instrument at low wind speeds. At high wind speeds, however, blowing snow still caused the instrument to register incorrectly. For this reason, a Vector Instruments A100 cup anemometer was mounted alongside the DAT-300 to provide an additional indication of mean wind speed. Temperature and humidity were measured at nominal heights of 4 and $2 \mathrm{~m}$ using Vaisala HMP35A probes in RM Young model $43408 \mathrm{H}$ artificially aspirated radiation shields. Relative humidities measured with these probes were adjusted for temperature dependence using the recalibration procedure of Anderson (1994). A further (and potentially more accurate) measurement of humidity was available from a DP3-D dew-point hygrometer (MBW Elektronik $\mathrm{AG})$, which sampled air at $4 \mathrm{~m}$ using a $6 \mathrm{~m}$ long heated sample tube (King and Anderson, 1999). The inlet to the sample tube pointed west (i.e. away from the prevailing wind direction) to avoid contaminating humidity measurements with wind-borne snow. Snow surface temperatures were measured using a Heitronics KT19 infrared thermometer and a platinum resistance thermometer that was maintained in contact with the snow surface.

The actual height of the instruments above the snow surface was measured daily and was adjusted annually to compensate for approximately $1.5 \mathrm{~m}$ annual snow accumulation. Readings from all of these instruments were digitized and recorded as $10 \mathrm{~min}$ means, which were later turned into $1 \mathrm{~h}$ means following quality control. In this paper, we make use of data recorded between January 1995 and January 1997.

\subsection{Calculation of sublimation}

\subsubsection{Surface sublimation}

We have used a bulk-transfer approach to calculate sublimation from the snow surface. The surface stress, $\tau$, sensible-heat flux, $H_{\mathrm{S}}$, and water-vapour flux, $E$, are related to differences between wind speed, $u$, temperature, $T$, and mixing ratio, $Q$,

Table 1. Deployment of the instruments used in this study

Instrument $\quad$ Manufacturer and type Nominal height

$\mathrm{m}$

Sonic anemometer

Cup anemometer

Frost-point hygrometer

Temperature/humidity probe

Temperature/humidity probe

Infrared thermometer

Contact thermometer
Kaijo Denki DAT 300

Vector Instruments A100

MBW Elektronic DP3-D

Vaisala HMP35A

Vaisala HMP35A

Heitronics KT19

Rhopoint Pt100, 1/30 DIN at some reference height $z_{\mathrm{R}}$ and values of the same variables at the snow surface (signified by subscript zero) through

$$
\begin{aligned}
\tau & =\rho C_{\mathrm{D}} u\left(z_{\mathrm{R}}\right)^{2} \\
H_{\mathrm{S}} & =\rho c_{\mathrm{P}} C_{\mathrm{H}} u\left(z_{\mathrm{R}}\right)\left(T\left(z_{\mathrm{R}}\right)-T_{0}\right) \\
E & =\rho C_{\mathrm{Q}} u\left(z_{\mathrm{R}} R\right)\left(Q\left(z_{\mathrm{R}}\right)-Q_{0}\right),
\end{aligned}
$$

where $C_{\mathrm{D}}, C_{\mathrm{H}}$ and $C_{\mathrm{Q}}$ are, respectively, the bulk-transfer coefficients for momentum, heat and water vapour, $c_{\mathrm{p}}$ is the specific heat capacity of air at constant pressure and $\rho$ is the air density. In order to calculate fluxes using Equation (1), it is necessary to determine these coefficients which, in general, will depend on both surface roughness and atmospheric stability. The bulk-transfer coefficients are related to the integrated forms of the surface-layer similarity functions by:

$$
\begin{aligned}
C_{\mathrm{D}}= & \left.\kappa^{2}\left[\left(\ln \left(z_{\mathrm{R}}\right) / z_{0}\right)-\Psi_{\mathrm{M}}\left(z_{\mathrm{R}}\right) / L\right)\right]^{-2} \\
C_{\mathrm{H}}= & \left.\kappa^{2}\left[\left(\ln \left(z_{\mathrm{R}}\right) / z_{0}\right)-\Psi_{\mathrm{M}}\left(z_{\mathrm{R}}\right) / L\right)\right]^{-1} \\
& \left.\cdot\left[\left(\ln \left(z_{\mathrm{R}}\right) / z_{\mathrm{H}}\right)-\Psi_{\mathrm{H}}\left(z_{\mathrm{R}}\right) / L\right)\right]^{-1} \\
C_{\mathrm{Q}}= & \left.\kappa^{2}\left[\left(\ln \left(z_{\mathrm{R}}\right) / z_{0}\right)-\Psi_{\mathrm{M}}\left(z_{\mathrm{R}}\right) / L\right)\right]^{-1} \\
& \left.\cdot\left[\left(\ln \left(z_{\mathrm{R}}\right) / z_{\mathrm{Q}}\right)-\Psi_{\mathrm{Q}}\left(z_{\mathrm{R}}\right) / L\right)\right]^{-1},
\end{aligned}
$$

where $\kappa$ is von Kármán's constant (taken to be 0.4$), z_{0}, z_{\mathrm{H}}$ and $z_{\mathrm{Q}}$ are the roughness lengths for momentum, heat and water vapour, respectively, and $\Psi_{\mathrm{M}}, \Psi_{\mathrm{H}}$ and $\Psi_{\mathrm{Q}}$ are the corresponding integrated forms of the surface-layer similarity functions, which express how profiles of wind speed, temperature and humidity deviate from the logarithmic forms that are observed under neutral conditions $(z / L=0)$ as a result of stability effects. These functions depend solely on the dimensionless height $z / L$, where $L$ is the Monin-Obukhov length defined as:

$$
L=\frac{u_{*}^{3} T_{0} \rho C_{\mathrm{P}}}{\kappa g H_{\mathrm{S}}},
$$

where $u_{*}$ is the friction velocity, defined through $\tau=\rho u_{*}^{2}$. Since $L$ is a function of the fluxes to be calculated, the equations set (1-3) must generally be solved iteratively.

For stable stratification $(z / L>0)$, we have used the scheme of King and Connolley (1997) to calculate the integrated similarity functions, since this has proved to be robust under the strongly stable conditions that often prevail at Halley (King and others, 1996). In the unstable regime $(z / L<0)$ we set $\Psi_{\mathrm{M}}=\Psi_{\mathrm{H}}=\Psi_{\mathrm{Q}}=0$, i.e. we use the values of bulk-transfer coefficients appropriate to neutral conditions. The reason for doing this is that the flux-profile relationships commonly used in the unstable regime are extremely sensitive to temperature-gradient errors at low wind speeds. Applying this parameterization to the Halley data produces unrealistically high fluxes on occasion that bias the climatological means. We justify our use of neutral transfer coefficients on two grounds. Firstly, very unstable conditions rarely occur at Halley and will thus not contribute significantly to the long-term flux climatology. Upward heat fluxes were observed for $30 \%$ of the time between November and February, and only on $50 \%$ of these occasions did $\left|z_{\mathrm{R}} / L\right|$ exceed 0.05. Secondly, heat fluxes computed using our procedure are in better overall agreement with eddy-correlation measurements from the sonic anemometer than are fluxes computed using the standard unstable similarity functions.

When calculating transfer coefficients, we have set the value of momentum roughness length to that measured by King and Anderson (1994) at this same site $\left(5.6 \times 10^{-5} \mathrm{~m}\right)$. Inclusion of a parameterization to account for the increase 
in apparent roughness length under blowing-snow conditions (Chamberlain, 1983) makes little difference to computed monthly mean fluxes. We also set $z_{\mathrm{H}}=z_{\mathrm{Q}}=z_{0}$. The measurements of King and Anderson (1994) indicated $z_{\mathrm{H}} \gg z_{0}$, but they noted that this could be due to problems with surface temperature measurement. There are sound theoretical reasons (Andreas, 1987) for expecting $z_{\mathrm{H}}<z_{0}$ over snow surfaces, but measured values of $z_{\mathrm{H}}$ and $z_{\mathrm{Q}}$ (e.g. Bintanja and Van den Broeke, 1995) are quite scattered. We thus take an agnostic approach and, later in this paper, investigate the sensitivity of our calculations to changes in the scalar roughness lengths.

The surface-layer similarity theory underlying the calculation of transfer coefficients using Equation (2) is not strictly valid if there are sources or sinks of heat and/or water vapour between the surface and the reference height. Surface sublimation rates calculated using this technique may therefore be in error if blowing snow is present and is subliming. Bintanja (1998) describes a technique for estimating both surface and blowing-snow sublimation in a consistent manner. Using results from runs of a model in which blowing-snow microphysics was realistically represented, he developed parameterizations for blowing-snow and surface sublimation as a function of meteorological forcing variables (wind speed, temperature and humidity). These parameterizations can then be used to generate consistent estimates of surface and blowing-snow sublimation from observations. In this paper, we take a simpler approach which we believe is justified by the uncertainties in the measurements and calculations. Observations reported by Mann (1998) show that when blowing snow occurs at Halley, air in a layer from the surface upwards rapidly becomes saturated. This will act to reduce sublimation from the surface. We have thus modified our surface sublimation estimates by setting surface sublimation to zero when $u_{*}$ exceeds some threshold value, $u_{* t}$, above which blowing snow is observed to occur. Mann and others (2000) obtain values of $0.25-0.39 \mathrm{~m} \mathrm{~s}^{-1}$ for $u_{* \mathrm{t}}$ at Halley. We have used $u_{* \mathrm{t}}=0.3 \mathrm{~m} \mathrm{~s}^{-1}$, and below we estimate the uncertainty in surface sublimation associated with uncertainties in the value of this parameter.

We have computed the water-vapour flux, $E$, from Equations (1-3), using hourly mean values of wind speed, temperature and humidity at $z_{\mathrm{R}}=4 \mathrm{~m}$, together with values of surface temperature. The surface mixing ratio, $Q_{0}$, was taken as the mixing ratio of air saturated with respect to ice at the snow surface temperature, $T_{0}$. At low wind speeds, icing of the cup anemometer caused this instrument to read incorrectly, so wind speed was taken from the sonic anemometer if $u<7 \mathrm{~m} \mathrm{~s}^{-1}$. For higher wind speeds (when the sonic anemometer readings may have been affected by blowing snow) the cup anemometer was used. The vapour pressure at $z=z_{\mathrm{R}}$ was obtained from the frost-point hygrometer and was converted to a mixing ratio using atmospheric pressure measured at the station. Factors affecting the accuracy of these humidity measurements are discussed by King and Anderson (1999). We estimate that the uncertainty in frost points measured with this instrument does not exceed $\pm 0.5^{\circ} \mathrm{C}$ over the range of conditions encountered. Surface temperatures were taken from the infrared thermometer, which was calibrated using a black-body target in an environmental chamber. Surface brightness temperatures were converted to actual surface temperatures using an emissivity of 0.98 (Warren, 1982). The temperatures thus obtained generally agreed well with temperatures measured using the contact thermometer at times when the latter was unaffected by solar radiation. On occasions, infrared thermometer snow surface temperatures were observed to rise several ${ }^{\circ} \mathrm{C}$ above freezing point. The reasons for this unrealistic behaviour are not well understood, but it possibly indicates some sensitivity of the device to reflected solar radiation. In such cases, the snow surface temperature was set to $0.0^{\circ} \mathrm{C}$.

\subsubsection{Blowing-snow sublimation}

Following Schmidt (1972), the total column sublimation rate of blowing snow $\mathrm{d} M / \mathrm{d} t$ can be deduced by calculating the sublimation rate for a single particle, $\mathrm{d} m / \mathrm{d} t$, of radius $r$ at height $z$ and then using the frequency distribution for particle size $f(r, z)$ and a vertical profile of total snow-particle number density $N(z)$ to give

$$
\frac{\mathrm{d} M}{\mathrm{~d} t}=\int_{0}^{h} \int_{0}^{\inf } \frac{\mathrm{d} m}{\mathrm{~d} t}(r, z) N(z) f(r, z) \mathrm{d} r \mathrm{~d} z,
$$

where $h$ is the height of the column of blowing snow. In order to calculate the column sublimation rate using Equation (4) above, it is necessary to develop expressions for the sublimation rate of a single particle as a function of particle size and height and for the particle size distribution and particle number density as a function of height.

For the sublimation rate for a single particle, we use the expression derived by Schmidt (1972) using the method of Thorpe and Mason (1966). Further details are given in Mann (1998) and Mann and others (2000). Particle sublimation rates depend on ambient temperature and humidity. In order to calculate single particle sublimation rates as a function of height, it is thus necessary to fit analytical profiles of temperature and humidity to the measurements made at 2 and $4 \mathrm{~m}$. Analysis of temperature and humidity profiles recorded during blowing-snow episodes at Halley in 1991 (Mann, 1998) suggested that a linear fit to the temperature measurements and a decreasing exponential fit to the relative humidity measurements was appropriate. The humidity profile was further constrained by requiring $100 \%$ relative humidity (with respect to ice) at the snow surface.

Blowing-snow particles have been found to have a distribution of radii which can be modelled by a two-parameter gamma distribution (Budd, 1966; Schmidt, 1982; Dover, 1993). Using this distribution, the probability $\operatorname{Pr}_{\alpha, \beta}(r)$ of a particle having radius in the range $(r, r+\delta r)$ is given by

$$
\operatorname{Pr}_{\alpha, \beta}(r)=\frac{\mathrm{e}^{-(r / \beta)} r^{\alpha-1}}{\beta^{\alpha} \Gamma(\alpha)} \delta r,
$$

where $\alpha$ is the shape parameter, $\beta$ is the scale parameter and $\Gamma(\alpha)$ is the gamma function.

Dover (1993) analyzed measurements of snow particle size made at Halley during austral winter 1991 and showed that mean particle radius, $\bar{r}$ (in $\mu \mathrm{m}$ ), as a function of height (in $\mathrm{m}$ ) was well described by

$$
\bar{r}=\beta \alpha=75.0-3.78 z .
$$

Smith (1995) developed approximate analytical solutions for column sublimation and showed that for it to be non-zero and finite, the value of $\alpha$ can only be 2. Dover's (1993) measurements support this value and we fix $\alpha=2$ in our analysis.

Equation (6) is based on measurements made between 0.1 and $4 \mathrm{~m}$. Extrapolation of the parameterization for use on snow particles above this height requires much care. In Mann (1998), the $12 \mathrm{~m}$ column sublimation was calculated 
from blowing-snow density measurements assuming $\bar{r}$ varied as in Equation (6) between 0.1 and $4 \mathrm{~m}$ but remained constant above that height. This was reasonable over the $12 \mathrm{~m}$ height range considered in that study. In this study, however, a parameterization is required for the variation in $\bar{r}$ up to $50 \mathrm{~m}$. Given that particles will sublime during transport and that smaller particles will be carried higher than larger ones, we use an exponentially reducing mean particle radius

$$
\bar{r}=\begin{array}{cc}
a+b z & z<4 \mathrm{~m} \\
c \exp (-d z) & z \geq 4 \mathrm{~m}
\end{array}
$$

with $a$ and $b$ from Equation (6) and $d=-b /(a+4 b)$ and $c=(a+4 b) \exp (4 d)$ to ensure continuity and differentiability at $z=4 \mathrm{~m}$.

A parameterization for the variation of blowing-snow particle density with wind speed was developed by Mann (1998) from blowing-snow measurements made at Halley in 1991. The parameterization is based on the assumption that sublimation can be neglected and a balance exists between gravitational settling and turbulent diffusion of snow particles, producing a steady-state particle concentration profile. This implies that the total particle number density $N\left(z, u_{*}\right)$ varies with friction velocity $u_{*}=\tau^{1 / 2}$ and height $z$ as

$$
N\left(z, u_{*}\right)=N_{\mathrm{r}}\left(u_{*}\right)\left(\frac{z}{z_{\mathrm{r}}}\right)^{-\left(w_{\mathrm{f}}\left(u_{*}\right) / k u_{*}\right)} .
$$

$w_{\mathrm{f}}\left(u_{*}\right)$ is an average particle fall speed. Strictly, Equation (8) should only be applied to particles of a single size. However, particle number-density profile measurements made at Halley (Mann, 1998) show that Equation (8) represents the total particle number-density profile quite well if $w_{\mathrm{f}}$ is parameterized as:

$$
w_{\mathrm{f}}=g_{1} \min \left(u_{*}, u_{*}^{\mathrm{cut}}\right)
$$

with $g_{1}=0.3056$ and $u_{*}^{\text {cut }}=0.375 \mathrm{~m} \mathrm{~s}^{-1} . N_{\mathrm{r}}\left(u_{*}\right)$ is a number density at some reference height, $z_{\mathrm{r}}$, which was found from particle-counter measurements at $0.1 \mathrm{~m}$ to vary with friction velocity as

$$
N_{\mathrm{r}}\left(u_{*}\right)=h_{1}\left(u_{*}-u_{* \mathrm{t}}\right)^{h_{2}} .
$$

$h_{1}$ and $h_{2}$ are the coefficients of best fit found by the method of least squares for the chosen threshold friction velocity $u_{* \mathrm{t}}$ below which there is no blowing snow. Blowing-snow particle number densities $\left(\right.$ in $\mathrm{m}^{-3}$ ) for the whole of winter 1991 are well fitted by Equation (10) with $u_{* \mathrm{t}}=0, h_{1}=1.12 \times 10^{8}$ and $h_{2}=4.383$, with $u_{*}$ in $\mathrm{m} \mathrm{s}^{-1}$. Using $u_{* \mathrm{t}}=0$ may appear to be inconsistent with the previous section, in which a non-zero threshold value was used. However, studies of individual blowing-snow events during 1991 show large variations in the threshold friction velocity, $u_{* t}$. Although Equation (10) with $u_{* \mathrm{t}}=0$ implies that blowing snow is present at all wind speeds, the predicted concentrations are small for $u_{*}$ values less than about $0.3 \mathrm{~m} \mathrm{~s}^{-1}$, and the overall fit to the data is better than if a fixed, non-zero threshold is chosen.

We have checked our procedure for calculating blowingsnow sublimation by applying it to data collected at Halley during austral winter 1991. Mann and others (2000) have calculated blowing-snow sublimation from these data. While their technique is similar in essence to that described in the present paper, it differs in two important respects. First, humidity measurements were available at five levels in 1991, thus improving the definition of the humidity profile. Second, snow particle concentration was measured using particle
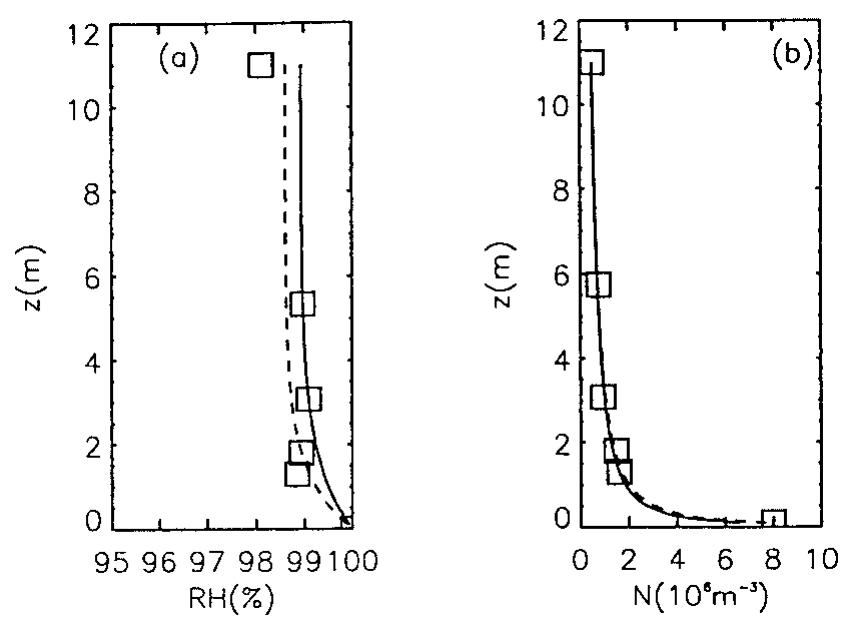

Fig. 1. Typical $1 \mathrm{~h}$ average profiles of $($ a ) relative humidity with respect to ice and ( $b$ ) blowing-snow particle number density measured during a blowing-snow event in winter 1991 at Halley. Measurements are indicated by squares. In (a), the broken line is a fit to all measurement levels, and the solid line is a fit to only two levels. In (b) the broken line is a fit to the data, and the solid line is the number density profile predicted using the parameterization presented in this paper.

counters at six levels, so it was not necessary to use the parameterization for $N(z)$ presented above. The blowing-snow sublimation estimates made by Mann and others (2000) are thus better constrained than those reported here. Applying our technique to the 1991 data and comparing with the results of Mann and others (2000) gives an indication of the errors inherent in making blowing-snow estimates using the cruder data available for 1995-97.

Figure la shows a typical $1 \mathrm{~h}$ mean humidity profile from winter 1991. Also shown are the decreasing exponential fits to all five measurements, as used by Mann and others (2000), and to just two levels (at around 3 and $6 \mathrm{~m}$ ), as used in the present study. The two-level fit slightly overestimates humidity in the upper part of the profile, leading to an underestimate of blowing-snow sublimation. In Figure $1 b$, measurements of snow particle density, $N(z)$, are shown, together with a power-law fit to the data (as used by Mann and others (2000)) and an estimate of $N(z)$ using the parameterization described above. In this case, the parameterization provides a very good fit to the observations, but it uses a fixed threshold friction velocity, while Mann and others (2000) show that this quantity varied considerably throughout winter 1991. Parameterized blowingsnow concentrations are sometimes greater than and sometimes less than those observed, leading to large differences between the blowing-snow sublimations calculated using the two procedures.

The impact of these uncertainties is illustrated in Table 2. Here we have calculated total blowing-snow sublimation for four blowing-snow events during winter 1991 that were studied by Mann and others (2000). The events lasted 1-3 days and, according to the calculations of Mann and others (2000), gave rise to total blowing-snow sublimation of $0.24-0.65 \mathrm{~mm}$ w.e. Recalculation of these figures using relative humidity measurements at only two levels reduces sublimation totals by up to $24 \%$. Using parameterized rather than observed particle densities causes changes of both signs of up to $60 \%$. Uncertainty in the parameterized blowing-snow particle density is thus the largest contributor to errors in our sublimation calculation. 
Table 2. Blowing-snow sublimation ( $m$ m w.e.) calculated for four blowing-snow events during winter 1991 at Halley

\begin{tabular}{lclcc}
\hline & \multicolumn{4}{c}{ Event no. } \\
& 1 & 2 & 3 & 4 \\
\hline Length (days) & 2.9 & 2.1 & 1.2 & 1.5 \\
A & 0.649 & 0.381 & 0.242 & 0.257 \\
B & 0.577 & 0.291 & 0.213 & 0.213 \\
C & 1.044 & 0.17 & 0.329 & 0.087 \\
D & 0.948 & 0.135 & 0.292 & 0.073 \\
& & & & \\
\hline
\end{tabular}

Notes: Estimates were made as follows:

A. Using the technique described by Mann and others (2000).

B. As A, but only using humidity measurements at two levels.

C. As A, but using the parameterization for particle density described in this paper in place of measurements.

D. Using the technique described in the present paper.

\section{RESULTS}

\subsection{Surface sublimation}

The variation of wind speed, temperature and relative humidity throughout our study period is illustrated in Figure 2. Monthly mean values of calculated surface sublimation, expressed as mmw.e. $\mathrm{d}^{-1}$, are shown in Figure 3. Between April and October, the measurements indicate small negative sublimation rates, i.e. net deposition of water vapour onto the snow surface. This is in agreement with the results of King and others (1996), who measured small, generally downward fluxes of water vapour during winter 1991 at Halley. During

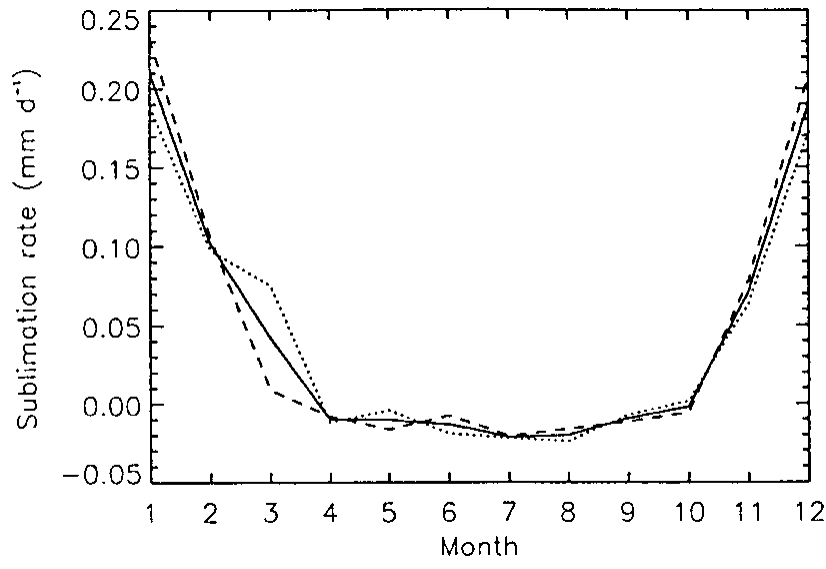

Fig. 3. Monthly mean surface sublimation rate at Halley for 1995 (dotted line), 1996 (dashed line) and the mean of both years (solid line).

these winter months, net radiative cooling of the surface is balanced by downward turbulent heat flux, leading to the establishment of a stable temperature gradient near the surface and an associated increase in humidity mixing ratio with increasing height. Between November and February, solar heating of the snow surface exceeds longwave cooling, driving upward fluxes of heat and water vapour and reversing the temperature and humidity gradients. During this summer period, monthly mean surface sublimation rates are typically $0.15-0.2$ mm w.e. $\mathrm{d}^{-1}$.

The sensitivity of the calculated surface sublimation rates to measurement errors and to variations in the assumed scalar roughness lengths and threshold friction velocity is illustrated in Table 3 . A systematic error of $0.5^{\circ} \mathrm{C}$
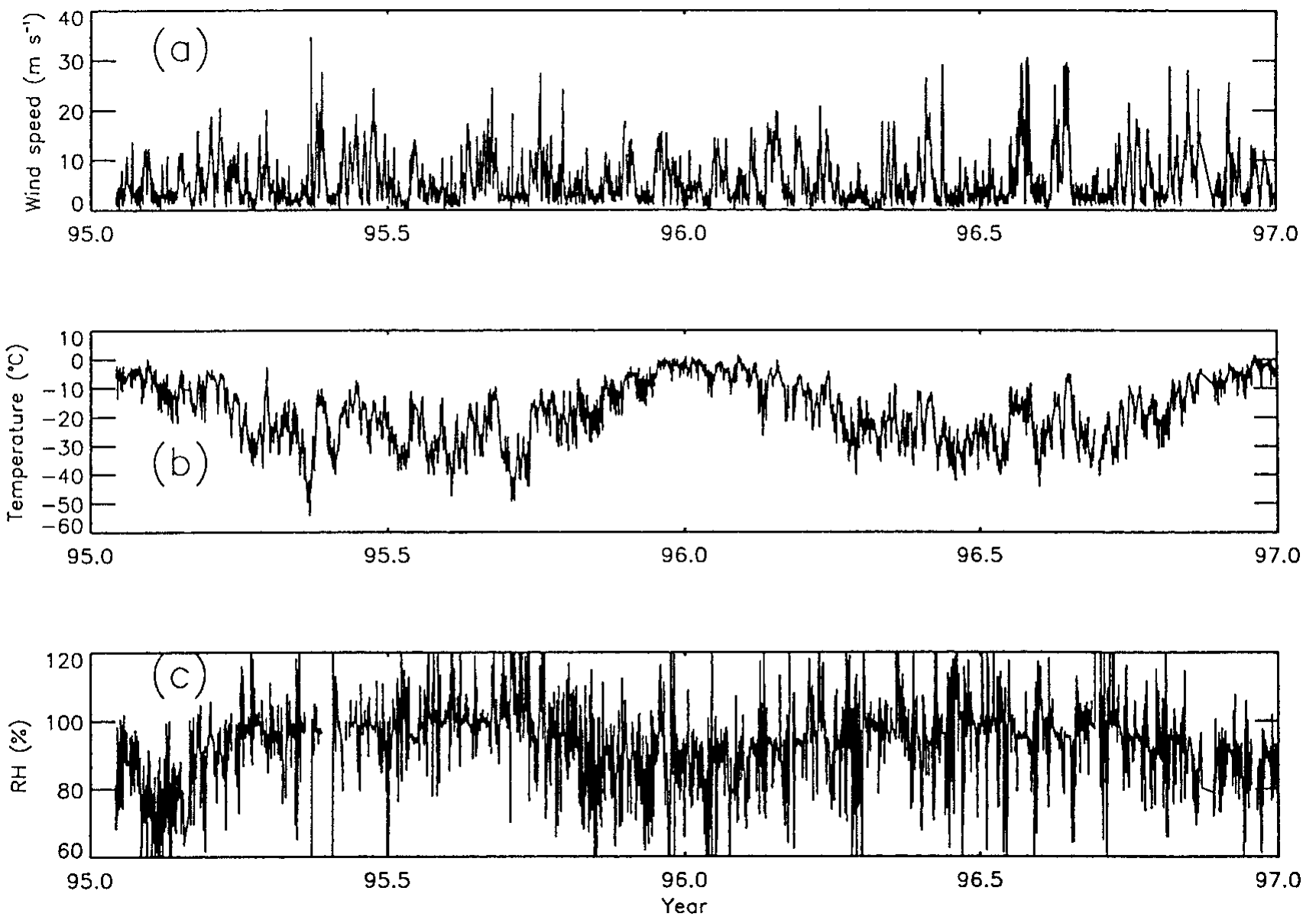

Fig. 2. Hourly mean values of ( a ) wind speed, (b) temperature and (c) relative humidity with respect to ice, all at a height of $4 \mathrm{~m}$. 
Table 3. Sensitivity of the absolute value of monthly mean surface sublimation to systematic offsets in surface temperature $\left(T_{0}\right), 4 m$ frost-point temperature $\left(T_{\mathrm{F}}\right)$ and changes in the ratio of scalar to momentum roughness lengths and in the assumed threshold friction velocity, $u_{* \mathrm{t}}$

\begin{tabular}{lcc}
\hline Sensitivity test & \multicolumn{2}{c}{ Sublimation change } \\
& June & December \\
& $\%$ & $\%$ \\
\hline$T_{0}+0.5^{\circ} \mathrm{C}$ & -75 & +20 \\
$T_{0}-0.5^{\circ} \mathrm{C}$ & +70 & -22 \\
$T_{\mathrm{F}}(4 \mathrm{~m})+0.5^{\circ} \mathrm{C}$ & +81 & -23 \\
$T_{\mathrm{F}}(4 \mathrm{~m})-0.5^{\circ} \mathrm{C}$ & -78 & +22 \\
$z_{\mathrm{H}}=z_{\mathrm{Q}}=10 z_{0}$ & +21 & +27 \\
$z_{\mathrm{H}}=z_{\mathrm{Q}}=0.1 z_{0}$ & -14 & -17 \\
$u_{* \mathrm{t}}=0.25 \mathrm{~m} \mathrm{~s}^{-1}$ & -26 & -25 \\
$u_{* \mathrm{t}}=0.35 \mathrm{~m} \mathrm{~s}^{-1}$ & +14 & +34 \\
$u_{* \mathrm{t}}=\infty$ & +170 & +136 \\
\hline
\end{tabular}

in either the surface temperature or $4 \mathrm{~m}$ frost-point temperature changes winter surface sublimation rates by up to $80 \%$. However, the absolute values remain small. The same systematic offsets change the much larger summer sublimation rates by around $20 \%$.We believe that these temperature offsets represent an upper bound to uncertainties in our measurements, so the resulting sensitivities are a pessimistic estimate of errors in calculated sublimation. Both winter and summer sublimation rates change by around $20 \%$ when the ratio of the scalar roughness lengths, $z_{\mathrm{H}}$ and $z_{\mathrm{Q}}$, to the momentum roughness length, $z_{0}$, is varied by a factor of ten. Varying the threshold friction velocity, $u_{* t}$, above which surface sublimation is set to zero, by $0.05 \mathrm{~m} \mathrm{~s}^{-1}$, can change monthly mean sublimation rates by $>30 \%$. Removing this restriction entirely more than doubles calculated surface sublimation rates. This final figure should be regarded as an upper bound on surface sublimation, since, as argued above, the presence of subliming blowing snow will inevitably act to reduce surface sublimation.

\subsection{Blowing-snow sublimation}

Figure 4 shows monthly mean values of column total blowing-snow sublimation. Once again, values are seen to be very low during the winter months, in accordance with the earlier results of King and others (1996). Between October

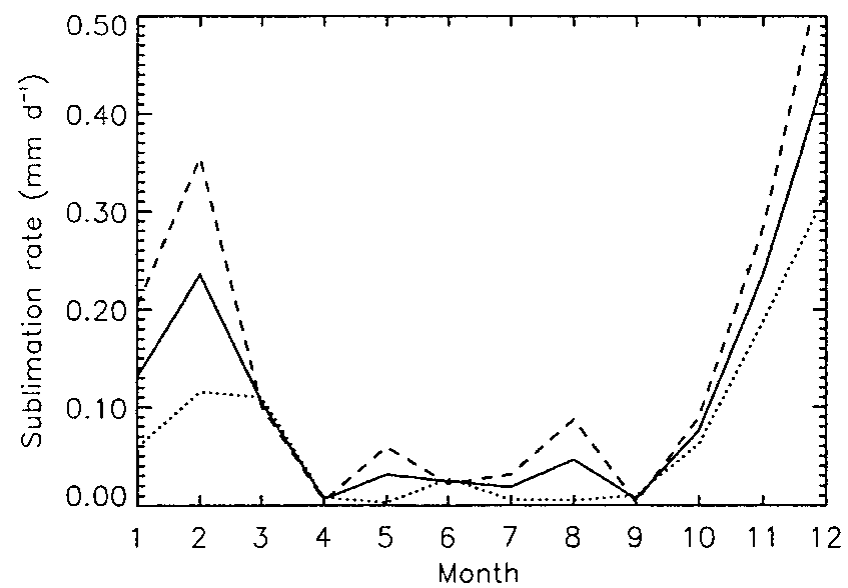

Fig. 4. Monthly mean column total blowing-snow sublimation rate at Halley for 1995 (dotted line), 1996 (dashed line) and the mean of both years (solid line).

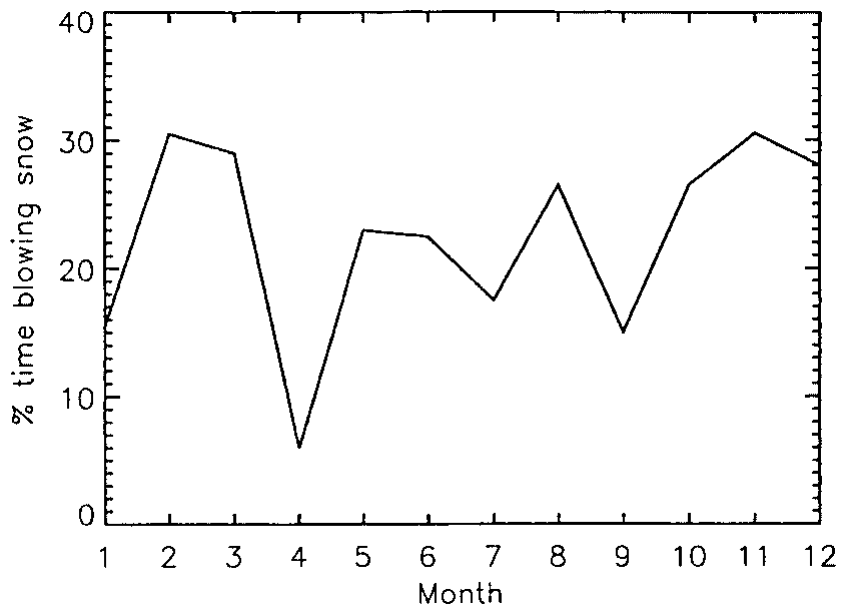

Fig. 5. Fraction of the time that blowing snow occurred at Halley for each month 1995/96, based on a threshold friction velocity $u_{* \mathrm{t}}=0.3 \mathrm{~ms}^{-1}$.

and March, blowing-snow sublimation rates increase significantly, exceeding the calculated surface sublimation rates. This reflects the higher temperatures and consequent increase in the mixing ratio of saturated air at this time of year. The fraction of the time for which blowing snow occurs (defined using a threshold friction velocity of $0.3 \mathrm{~ms}^{-1}$ ) shows little variation throughout the year (Fig. 5).

Table 4 illustrates the sensitivity of the blowing-snow sublimation calculation to systematic errors in some of the inputs. A $10 \%$ change in the wind speed used can change the calculated sublimation by a factor of 2 , illustrating the highly non-linear dependence of suspended snow density on wind speed (Equations (8-10)). The sensitivity to small errors in relative humidity is even greater. At the onset of blowing-snow events at Halley, relative humidity within the blowing-snow layer is observed to reach near-saturation with respect to ice quite rapidly as a result of sublimation, thus limiting further sublimation (Mann and others, 2000). If the humidity used in the calculation is artificially reduced, calculated sublimation will remain large throughout the blowing-snow event.

\subsection{Comparison with stake measurements}

We have made an independent estimate of sublimation rates from daily records of snow surface-level changes at an array of stakes at Halley. These measurements were made during

Table 4. Sensitivity of calculated monthly mean blowingsnow sublimation to systematic offsets in $4 \mathrm{~m}$ wind speed (u), temperature at 4 and $2 \mathrm{~m}(T)$ and relative humidity at 4 and $2 m(R H)$

\begin{tabular}{lcc}
\hline Sensitivity test & \multicolumn{2}{c}{ Sublimation change } \\
& fuly & fanuary \\
& $\%$ & $\%$ \\
\hline$u(4 \mathrm{~m})+10 \%$ & +84 & +84 \\
$u(4 \mathrm{~m})-10 \%$ & -48 & -48 \\
$T+0.2^{\circ} \mathrm{C}$ & +42 & +4 \\
$T-0.2^{\circ} \mathrm{C}$ & -35 & -4 \\
$\mathrm{RH}+2 \%$ & -96 & -34 \\
$\mathrm{RH}-2 \%$ & +800 & +36
\end{tabular}


7 years between 1973 and 1982. Monthly total precipitation, $P$, was estimated as

$$
P=\rho_{1} \Sigma+,
$$

where $\rho_{1}$ is a mean density for freshly fallen snow and $\Sigma+$ is the sum of daily level changes for all days on which the surface level rose. Monthly net accumulation, $A$, was estimated as

$$
A=\rho_{2} \Sigma,
$$

where $\rho_{s}$ is the mean density of the surface snowpack and $\Sigma$ is the net surface-level change for the month. The net sublimation, $S$, can then be deduced from the surface mass balance

$$
A=P-S-R,
$$

where $R$ represents the amount of snow removed as a result of blowing-snow transport divergence. Without accurate measurements of the spatial variations in wind speed around Halley, it is difficult to estimate $R$ accurately. However, there is some evidence that systematic spatial variations in wind speed are small. During January 1992, meteorological observations were made at both Halley 4 and Halley 5 stations, which are separated by about $15 \mathrm{~km}$ in an east-west direction (i.e. roughly in the direction of the prevailing wind). These measurements show that, under strong wind conditions, the wind speed at the two stations was the same to within $\pm 0.5 \mathrm{~m} \mathrm{~s}^{-1}$, this being the precision with which the measurements were recorded. Taking this as an absolute maximum difference, we computed total blowing-snow transport for 1995/96 from our wind measurements (using the parameterization proposed by Mann and others, 2000) and then repeated the calculation using the same wind-speed measurements enhanced by $0.5 \mathrm{~m} \mathrm{~s}^{-1}$. For stations separated by $15 \mathrm{~km}$, the results imply an upper bound to the annual removal (or deposition) of blowing snow of around $7 \mathrm{~mm}$ w.e. This is small compared to total sublimation and can be neglected, so the net sublimation is simply given by $S=P-A$. The greatest errors in this estimate of $S$ come from uncertainties in the densities $\rho_{1}$ and $\rho_{2}$.

Table 5 shows monthly mean totals of sublimation estimated by this method together with summed surface and blowing-snow sublimation totals. Given the large uncertainties inherent in both techniques, agreement is fair, particularly for the November-January period. It is much poorer during the winter months, when the errors inherent in the stake technique are at least as large as the small mean fluxes observed. How-

Table 5. Comparison of calculated surface plus blowing-snow sublimation (S), 1995/96, with the difference between precipitation $(P)$ and accumulation ( $A$ ) estimated from daily snow-stake measurements, 1973-82. Units are mm w.e.

\begin{tabular}{lrrrr}
\hline Month & $P$ & $A$ & $P-A$ & $S$ \\
\hline 1 & 43.6 & 28.0 & 15.7 & 10.6 \\
2 & 66.8 & 63.2 & 3.6 & 9.5 \\
3 & 52.6 & 50.7 & 1.9 & 4.6 \\
4 & 73.9 & 70.4 & 3.5 & -0.1 \\
5 & 56.0 & 48.6 & 7.5 & 0.7 \\
6 & 53.4 & 54.2 & -0.7 & -0.3 \\
7 & 33.0 & 26.2 & 6.7 & -0.1 \\
8 & 38.8 & 35.7 & 3.1 & 0.8 \\
9 & 26.0 & 24.1 & 1.9 & -0.1 \\
10 & 58.3 & 61.9 & -3.6 & 2.3 \\
11 & 24.8 & 5.6 & 19.2 & 9.2 \\
12 & 28.4 & 5.2 & 23.2 & 19.7 \\
Year & 555.6 & 473.8 & 82.0 & 57.3 \\
& & & & \\
\hline
\end{tabular}

ever, the stake observations support our finding that sublimation is negligibly small during the winter months.

\section{DISCUSSION}

Our results indicate, in accordance with the earlier study of King and others (1996), that sublimation and deposition make an insignificant contribution to the surface mass balance at Halley during the winter months. Between November and March, however, sublimation becomes significant and removes around $25 \%$ of the snow falling during this period, or $10 \%$ of the total annual precipitation. Surface and blowing-snow sublimation appear to be comparable during the summer period, but the uncertainties in both estimates are quite large. The agreement between estimates of summer sublimation using micrometeorological and snow-stake data is reasonably good and gives us some confidence in our estimates.

Few comparable measurements exist for other Antarctic stations. Surface sublimation at Mizuho $\left(70.7^{\circ} \mathrm{S}, 44.3^{\circ} \mathrm{E}\right.$; $2230 \mathrm{~m}$ a.s.l.) is also insignificant during the winter months, and reaches values comparable to those observed at Halley during the summer period (Fujii, 1979). While the annual mean wind speed is significantly greater at Mizuho $\left(9.5 \mathrm{~m} \mathrm{~s}^{-1}\right)$ than at Halley $\left(6.2 \mathrm{~m} \mathrm{~s}^{-1}\right)$, Mizuho experiences significantly lower temperatures (annual mean $-31.3^{\circ} \mathrm{C}$, cf. $-19.3^{\circ} \mathrm{C}$ at Halley). Surface sublimation rates over the Ross Ice Shelf calculated from automatic weather station data (Stearns and Weidner, 1993) are comparable with our Halley observations. Bintanja (1998) calculated monthly blowing-snow sublimation totals of up to $25 \mathrm{~mm}$ for automatic weather station sites in the strong katabatic wind zone of Terre Adélie. Even during winter, his calculations show monthly totals of around $10 \mathrm{~mm}$ at the windiest stations. While this partly reflects the windier climate of this region, Bintanja's estimates may be inflated because, in the absence of humidity measurements from the automatic weather stations, he assumed a fixed background relative humidity of $70 \%$ to drive his model.

As discussed by Mann and others (2000), our Halley measurements point to a strong negative feedback mechanism, where the near-surface air rapidly becomes nearly saturated with respect to ice as a result of sublimation at the onset of a blowing-snow event, thus limiting further sublimation, both of blowing snow and from the surface. It seems likely that this mechanism will operate over much of Antarctica, but it may be less effective in the strong katabatic wind zone, where the advection of dry, adiabatically warmed descending air may help to maintain high sublimation rates. Further measurements are needed to see how representative our Halley measurements are of the continent as a whole.

\section{ACKNOWLEDGEMENTS}

The measurements reported in this paper were funded in part by the European Commission Environment Programme, under contract No. ENV4-CT95-0076 "Polar Snow". G.W.M. was supported by a CASE studentship from the U.K. Natural Environment Research Council. We thank D.W. S. Limbert and S. R. Colwell for providing the snow-stake estimates of sublimation,and members of the 1995 and 1996 wintering teams at Halley for maintaining the instruments used in this 
study. Thanks are also due to referees R. Bintanja and G. Kaser for their constructive criticism of our original manuscript.

\section{REFERENCES}

Anderson, P. S. 1994. A method for rescaling humidity sensors at temperatures well below freezing. 7. Atmos. Oceanic Technol., 11 (5), 1388-1391.

Andreas, E. L. 1987. A theory for the scalar roughness and the scalar transfer coefficients over snow and sea ice. Boundary-Layer Meteorol., 38(1-2), 159-184.

Bintanja, R. 1998. The contribution of snowdrift sublimation to the surface mass balance of Antarctica. Ann. Glaciol., 27, 251-259.

Bintanja, R. and M. R. van den Broeke. 1995. Momentum and scalar transfer coefficients over aerodynamically smooth Antarctic surfaces. BoundaryLayer Meteorol., 74(1-2), 89-111.

Budd, W. F. 1966. The drifting of non-uniform snow particles. In Rubin, M. J., ed. Studies in Antarctic meteorology. Washington, DC, American Geophysical Union, 59-70. (Antarctic Research Series 9.)

Chamberlain, A. C. 1983. Roughness length of sea, sand and snow. BoundaryLayer Meteorol., 25(4), 405-409.

Dover, S. E. 1993. Numerical modelling of blowing snow. (Ph.D. thesis, University of Leeds.)

Fujii, Y. 1979. Sublimation and condensation at the ice sheet surface of Mizuho station, Antarctica. Antarct. Rec., 67, 51-63.

King, J. C. 1990. Some measurements of turbulence over an Antarctic ice shelf. Q. F. R. Meteorol. Soc., 116(492), 379-400.

King, J. C. and P. S. Anderson. 1994. Heat and water vapour fluxes and scalar roughness lengths over an Antarctic ice shelf. Boundary-Layer Meteorol., $69(1-2), 101-121$.

King, J. C. and P. S. Anderson. 1999. A humidity climatology for Halley, Antarctica, based on frost-point hygrometer measurements. Antarct. Sci., 11(1), 100-104
King, J. C. and W. M. Connolley. 1997. Validation of the surface energy balance over the Antarctic ice sheets in the U.K. Meteorological Office unified climate model. F. Climate, 10 (6), 1273-1287.

King, J. G., P. S. Anderson, M. C. Smith and S. D. Mobbs. 1996. The surface energy and mass balance at Halley, Antarctica during winter. f. Geophys. Res., 101(D14), 19,119-19,128.

König-Langlo, G., J. C. King and P. Pettré. 1998. Climatology of the three coastal Antarctic stations Dumont d'Durville, Neumayer and Halley. $\mathcal{F}$. Geophys. Res., 103 (D9), 10,935-10,946.

Mann, G.W. 1998. Surface heat and water vapour budgets over Antarctica. (Ph.D. thesis, University of Leeds.)

Mann, G.W., P. S. Anderson and S. D. Mobbs. In press. Profile measurements of blowing snow at Halley, Antarctica. F. Geophys. Res., 105(D19), 24,491-24,508.

Schmidt, R. A. 1982. Vertical profiles of wind speed, snow concentration and humidity in blowing snow. Boundary-Layer Meteorol., 23(2), 223-246.

Schmidt, R. A., Jr. 1972. Sublimation of wind-transported snow - a model. U.S. For. Serv. Res. Pap. RM-90.

Smith, M. C. 1995. The role of atmospheric processes in the Antarctic ice mass balance. (Ph.D. thesis, University of Leeds.)

Stearns, C. R. and G. A. Weidner. 1993. Sensible and latent heat flux estimates in Antarctica. In Bromwich, D. H. and C. R. Stearns, eds. Antarctic meteorology and climatology: studies based on automatic weather stations. Washington, DC, American Geophysical Union, 109-138. (Antarctic Research Series 61.)

Thorpe, A. D. and B. J. Mason. 1966. The evaporation of ice spheres and ice crystals. F. Appl. Phys., 17(4), 541-548.

Van den Broeke, M. R. 1997. Spatial and temporal variation of sublimation on Antarctica: results of a high-resolution general circulation model. $\mathcal{F}$. Geophys. Res., 102(D25), 29,765-29,778.

Warren, S. G. 1982. Optical properties of snow. Rev. Geophys. Space Phys., 20 (1), 67-89. 